\title{
Performance and intestinal microflora response of broilers to a probiotic mixture supplementation
}

\author{
Anca Gheorghe*1, Mihaela Hăbeanu ${ }^{1}$, Mihaela Dumitru ${ }^{1}$, Nicoleta \\ Aurelia Lefter ${ }^{1}$, Lavinia Idriceanu ${ }^{1}$ \\ *Corresponding author: anca.gheorghe@ibna.ro
}

${ }^{1}$ National Research and Development Institute for Animal Biology and Nutrition, Laboratory of Animal Nutrition, Balotesti, Calea Bucuresti no. 1, 077015, Ilfov, Romania.

\section{ABSTRACT}

The study evaluated the effects of a Lactobacillus strains probiotic mix on performance, carcass traits, organs size, and intestinal microflora in broilers. A total of 200 one-day-old unsexed broilers were allotted into 2 groups with 5 replicates (20 broilers/replicate). During the feeding trial (35 d) the broilers were fed with a control (basal diet) or probiotic (basal diet plus $3 \%$ probiotic mix L. acidophilus and L. plantarum, 1:1 ratio). The probiotic supplementation did not significantly influence the performance, carcass traits and organs size of broilers at slaughter age. No effect of probiotic supplementation on visceral weight or length was observed, except a higher of jejunum $(\mathrm{P}=0.007)$ and ileum $(\mathrm{P}=0.013)$ weights, and a tendency to higher the caecum length $(\mathrm{P}=0.070)$. The probiotic mix had no significant effect on the intestinal $\mathrm{pH}$, but it improved the microflora by decreasing the Enterobacteria and E. coli counts and increasing the Lactobacilli counts and Lactobacilli: E. coli ratio in the ileum and caecum $(\mathrm{P}<0.05)$. In conclusion, the probiotic mix (L. acidophilus and $L$. plantarum mix, 1:1 ratio) did not significantly affect the productive performance but had a positive effect on broilers' gut microflora.

Keywords: broiler, probiotic, productive performance, gut microflora

\section{INTRODUCTION}

Nowadays, in the context of emerging public health concern about antibiotic resistance and food safety, intensive studies have been conducted to investigate natural nutritional alternatives such as probiotics and their role to improve the poultry performance and their products (Al-Shawi, 2020).

FAO/WHO (2002) defined the probiotics as "mono or mixed strains of living microorganisms which confer a desirable health benefit on the host when used adequately". The species of microorganisms used as probiotics for poultry included Lactobacillus, Lactococcus, Bifidobacterium, Bacillus, Streptococcus, and fungi e. g. Saccharomyces (Hossain et al., 2012; Gadee et al., 
2017). The selection of probiotics is based on tolerance to gastrointestinal (GIT) conditions, the capacity to adhere to the GIT mucosa, and the competitive exclusion of pathogens (Gadee et al., 2017). The probiotics survival rate in manufacture, storage, transport, and their viability and characteristics are important criteria as well (Bajagai et al., 2016).

Probiotics supplementation, either as single or mixed strains, in commercial poultry production, has indicated positive responses on productive performance (Olnood et al., 2015; de Souza et al., 2018; Deng et al., 2020; Lokapirnasari et al., 2020), nutrient absorption and digestibility (Li et al., 2008; Awad et al., 2010), immunity (Awad et al., 2009; Fathi et al., 2017), gut microflora and inhibition of pathogens (Giannenas et al., 2012; Giannenas et al., 2014; Ciurescu et al., 2020; Deng et al., 2020; Gheorghe et al., 2020). It was demonstrated that multiple-strain and multi-species probiotics could have a synergistic effect by acting on different sites and providing various modes of action (Timmerman et al., 2004; Kazemi et al., 2019).

Lactobacillus strains are one of the most used probiotics, that have been revealed to increase the activity of intestinal enzymes and digestion (Awad et al., 2010) and to control GIT pathogenic microbial populations such as Escherichia coli, Salmonella, and coliforms, improving intestinal health (Hardy et al., 2013; Chen et al., 2017; Attia et al., 2017; De Cesare et al., 2020). Several studies investigated the effects of L. acidophilus on performance, metabolic function and gut health in broilers or rurally reared chickens (De Cesare et al., 2017; Forte et al., 2018; Gheorghe et al., 2020). Other researches have been focused on the efficacy of L. plantarum in broilers feed (Mountzouris et al., 2007; Hong et al., 2012; Peng et al., 2016). A previous study in pigs (Habeanu et al., 2016) evaluated the relation between sow's milk quality and litter performances and health status as effects of feeding 5\% hemp seeds in lactating sows and $2.5 \%$ feed additive (L. acidophilus $50 \%$ and L. plantarum $50 \%$ ) in piglets. The authors noticed that the dietary fatty acids (FA) composition positively affect the colostrum/ milk quality in term of polyunsaturated FA content and piglets performance and health. Moreover, the feed additive addition improved the growth performance response of piglets. Since limited reports are available on the effect of a combined $L$. acidophilus and $L$. plantarum supplementation, this study aimed to investigate the response of broilers to probiotic L. acidophilus and L. plantarum (1:1 ratio) supplementation on growth performance, carcass parameters, organs size and intestinal microflora.

\section{MATERIALS AND METHODS}

The research institute ethical committee (INCDBNA-Balotesti, Romania) approved the procedures used in this trial, following the European legislation (Directive 2010/63/EU). 


\section{Probiotic strains}

Lactic acid bacteria (LAB) strains ( $\mathrm{n}=5 ;$ L. acidophilus, L. brevis, L. fermentum, L. salivarius and L. plantarum), previously isolated from the GIT of healthy broiler chickens and stored at IBNA collection strains, were evaluated for their probiotic potentials (Dumitru et al., 2019; Dumitru et al., 2020). The overnight culture of each Lactobacillus isolates after an incubation at $37^{\circ} \mathrm{C}$ in anaerobic conditions was evaluated for purity and their viability for three weeks (Shokryazdan et al., 2014). The strains were kept at $-80^{\circ} \mathrm{C}$ in MRS broth medium with $20 \%$ glycerol (v/v) as previously described Sorescu et al. (2019).

Due to its ability to survive of several probiotic properties (low $\mathrm{pH}$ of the stomach, bile salts, capacity to colonize in the digestive tract, resistance of antibiotics, low temperatures values etc.), only two Lactobacillus strains ( $L$. acidophilus and L. plantarum) were selected as probiotic candidates for broiler feed.

\section{Broilers and experimental design}

Two hundred 1-day-old Cobb 500 mixed sex broilers $(43.89 \pm 1.09 \mathrm{~g})$ were randomly allotted into two groups with five replicates each (20 broilers/ replicate) and used for a feeding trial (1 to 35 days of age). Broilers were reared in climate-controlled conditions on floor pens $(2 \times 1 \mathrm{~m})$ with wood shaving litter. Each pen was equipped with manual feeders and nipple drinker line. A light regime of $23 \mathrm{~h}$ per day was provided until day 7 , and $20 \mathrm{~h}$ light per day until 35 days. The birds were immunised against Marek's, Newcastle and Gumboro diseases according to veterinary protocol.

Three-phase basal diets were formulated based on the chemical composition of feeds (OJEU, 2009) to meet the Cobb 500 broilers nutrient requirements (Table 1 ).

Birds were fed with a basal diet (corn-soybean meal) or a probiotic diet (basal diet with $3 \%$ probiotic mix added). The two Lactobacillus strains ( $L$. acidophilus and L. plantarum) selected as probiotic candidates were mixed 1:1 ratio and added in a proportion of $3 \%$ (concentration of $1 \times 10^{9} \mathrm{CFU} / \mathrm{mL}$ ) into the premix of basal diet for each phase and homogenised.

The feeds were administered in mash form. Water and feed were given ad libitum to the broilers.

The performance variables evaluated during the trial were broilers body weight (BW) by individually weighing per each phase and the overall period, and body weight gain (BWG) was calculated. Feed intake (FI) was also recorded to calculate feed conversion ratio (FCR) per each growth phase. Viability was determined as [100 - mortality (\%)]. 
Table 1. Components and nutrients composition of basal diets (as-fed basis)

\begin{tabular}{|c|c|c|c|}
\hline Ingredients (g/kg) & $\begin{array}{c}\text { Starter } \\
(1-10 d)\end{array}$ & $\begin{array}{c}\text { Grower } \\
(11-22 \text { d) }\end{array}$ & $\begin{array}{c}\text { Finisher } \\
(23-35 d)\end{array}$ \\
\hline Corn & 560.0 & 600.0 & 657.6 \\
\hline Soybean meal & 310.0 & 269.0 & 220.0 \\
\hline Corn gluten meal & 50.0 & 46.0 & 36.0 \\
\hline Sunflower oil & 28.0 & 35.0 & 40.0 \\
\hline Monocalcium phosphate & 18.2 & 17.0 & 15.0 \\
\hline Calcium carbonate & 14.7 & 13.9 & 12.7 \\
\hline Salt & 3.0 & 3.0 & 3.0 \\
\hline DL-Methionine & 1.5 & 2.0 & 1.9 \\
\hline L-Lysine $\mathrm{HCl}$ & 4.0 & 3.5 & 3.2 \\
\hline Choline $\mathrm{HCl}$ & 0.6 & 0.6 & 0.6 \\
\hline Vitamin-mineral premix ${ }^{1}$ & 10.0 & 10.0 & 10.0 \\
\hline Probiotic $^{2}$ & $(-) /(+)$ & $(-) /(+)$ & $(-) /(+)$ \\
\hline \multicolumn{4}{|l|}{ Calculated composition (g/kg) } \\
\hline Metabolisable energy $(\mathrm{MJ} / \mathrm{kg})^{3}$ & 12.61 & 12.97 & 13.31 \\
\hline Crude protein & 220 & 200 & 180 \\
\hline Lysine, total & 13.2 & 11.9 & 10.5 \\
\hline Lysine, digestible & 11.8 & 10.5 & 9.5 \\
\hline Methionine + cysteine, total & 9.8 & 8.9 & 8.2 \\
\hline Methionine + cysteine, digestible & 8.8 & 8.0 & 7.4 \\
\hline Calcium & 9.0 & 8.4 & 7.6 \\
\hline Available phosphorus & 4.5 & 4.2 & 3.9 \\
\hline Crude fibre & 35.4 & 33.1 & 30.4 \\
\hline
\end{tabular}

Note: ${ }^{1}$ Provided per kg diet: vitamin A, $4.47 \mathrm{mg}$; vitamin D3, $0.12 \mathrm{mg}$; vitamin E, $80 \mathrm{mg}$; vitamin K3, 4 mg; vitamin B1, 4 mg; vitamin B2, 9 mg; vitamin B6, 4 mg; vitamin B12, 0.020 mg; vitamin B5, 15 mg; vitamin B3, 60 mg; vitamin B9, 2 mg; Mn, 100 mg; Zn, 100 mg; Fe, 40 mg; Cu, 15 mg; I, 1.0 mg; Se, 0.30 mg; Co, 0.25 mg. ${ }^{2}(-)$, no probiotic; $(+), 3 \%$ probiotic (L. acidophilus and L. plantarum mixture, 1:1 ratio). ${ }^{3}$ calculated using regression equations (NRC, 1994).

\section{Sampling and analyses}

At the end of the trial (35 days), eight broilers/group were assigned for carcasses, digestive organs and intestinal segments evaluation. After the fasting period $(12 \mathrm{~h})$, the birds were slaughtered by cervical dislocation, followed by bleeding, plucked and eviscerated. The gizzard, liver, heart, pancreas, spleen, bursa and abdominal fat were removed and weighed. The intestinal segments (duodenum, jejunum, ileum, and cecum) also were removed and weighed. The results were given as relative weights or lengths ( $g$ or $\mathrm{cm} \%$ of life BW).

The digesta $\mathrm{pH}$ from fresh samples was determined in duplicate with a portable pH-meter (WTW ProfiLine $\mathrm{pH} 3310$, Germany) by inserting the $\mathrm{pH}$ meter electrode into the distal parts of each intestinal segment. 
Digesta from ileum and caecum were sampled in sterile tubes and stored at $-20^{\circ} \mathrm{C}$ until microbial analyses. A conventional technique was used for determination of bacterial populations (total bacteria, LAB, E. coli and Salmonella spp.), the digesta samples were serially diluted in saline solution and selective agar media were used as previously described Gheorghe et al. (2019). Bacterial counts values were expressed as log-10 colony-forming units (CFU)/g of intestinal digesta.

\section{Statistical analysis}

Experimental data were analysed using one-way ANOVA followed by the Tukey's test to compare the differences between means (SPSS v.20, 2011). Data results are presented as mean and standard error of the mean (SEM). Significant differences were considered at $\mathrm{P}<0.05$.

\section{RESULTS AND DISCUSSION}

\section{Growth performance}

As shown in Table 2, probiotic supplementation did not significantly affect the productive performance (BW, FI and FCR) during the grower phase and overall experimental period (5-week) compared with control.

Table 2. Effect of probiotic addition on productive performance of broilers ${ }^{1}$

\begin{tabular}{lcccc}
\hline Item & Control & Probiotic & SEM & P-value $^{*}$ \\
\hline Starter (1-10 d) & & & & \\
BWG (g/bird) & 219.21 & 220.05 & 4.13 & 0.937 \\
FI (g/bird) & 270.26 & 274.45 & 1.26 & 0.313 \\
FCR (g feed: g gain) & 1.23 & 1.25 & 0.01 & 0.646 \\
Grower (11-22 d) & & & & \\
BWG (g/bird) & 675.09 & 687.61 & 15.19 & 0.581 \\
FI (g/bird) & 1015.67 & 1030.41 & 1.24 & 0.876 \\
FCR (g feed: g gain) & 1.50 & 1.49 & 0.10 & 0.113 \\
Finisher (23-35 d) & & & & \\
BWG (g/bird) & 985.38 & 999.17 & 33.25 & 0.956 \\
FI (g/bird) & 2000.15 & 2050.86 & 32.52 & 0.991 \\
FCR (g feed: g gain) & 2.03 & 2.05 & 0.01 & 0.090 \\
\hline Overall period (1-35 d) & & & & \\
BWG (g/bird) & 1879.68 & 1906.83 & 32.45 & 0.886 \\
FI & 3286.08 & 3355.72 & 26.11 & 0.892 \\
(g/bird) & & & & \\
FCR (g feed: g gain) & 1.75 & 1.76 & 0.03 & 0.104 \\
Viability (\%) & 98 & 99 & 1.20 & 0.538 \\
\hline
\end{tabular}

Note: ${ }^{1}$ Means of 5 replicate pens ( $\mathrm{n}=20$ birds/pen); SEM, standard error of the mean; BWG, body weight gain; FI, feed intake; FCR, feed conversion ratio.

*Means within rows do not differ significantly $(\mathrm{P}>0.05)$. 
Our results agree with several studies which reported that single or multiple-strains probiotic supplementation have not significantly affected the growth performance of broilers (Khosravi et al., 2010; Waititu et al., 2014; Olnood et al., 2015; Fathi et al., 2017; de Souza et al., 2018; Ding et al., 2019; Gheorghe et al., 2020).

\section{Carcass traits and organ weights}

The probiotic addition did not affect the broilers carcass yield, major cutup traits and relative organ weights $(\mathrm{P}>0.05$; Table 3$)$.

Table 3. Effect of probiotic addition on broiler carcases and organ weights ${ }^{1}$

\begin{tabular}{lcccc}
\hline Item & Control & Probiotic & SEM & $\boldsymbol{P}_{\text {-value }}{ }^{*}$ \\
\hline Carcass weight, g & 1433.25 & 1490.67 & 19.27 & 0.149 \\
Carcass yield, \% & 70.70 & 70.66 & 0.42 & 0.906 \\
Breast, \% & 24.39 & 24.98 & 0.50 & 0.111 \\
Legs, \% & 19.60 & 19.32 & 0.15 & 0.311 \\
Abdominal fat, \% & 1.46 & 1.37 & 0.08 & 0.574 \\
\hline Relative organ weights (\% BW) & & & \\
\hline Gizzard & 1.52 & 1.44 & 0.057 & 0.523 \\
Liver & 2.12 & 2.15 & 0.052 & 0.776 \\
Heart & 0.47 & 0.46 & 0.017 & 0.885 \\
Spleen & 0.10 & 0.12 & 0.005 & 0.608 \\
Pancreas & 0.22 & 0.25 & 0.013 & 0.062 \\
Bursa & 0.12 & 0.15 & 0.009 & 0.094 \\
\hline
\end{tabular}

Note: ${ }^{1} \mathrm{n}=8$ samples per group; SEM, standard error of the mean; BW, body weight. *Means within rows do not differ significantly $(\mathrm{P}>0.05)$.

Similarly, de Souza et al. (2018) investigated multi-strains probiotics ( $L$. acidophilus, Bacillus subtilis, Bifidobacterium bifidum and Enterococcus faecium) in Cobb chick's fed and reported no effects on the growth performance, carcasses traits and chemical composition. Other research has also stated that probiotic addition did not influence the lymphoid and digestive organs (Awad et al., 2009; Naseem et al., 2012). Pourakbari et al. (2016), using different doses of commercial multi-strains probiotics, reported variation in the responses of performance and carcass parameters, but no effects on immune organs or immune response. These authors also suggested that the optimum concentration of probiotics in broiler feed differs with the microorganism used in the product composition.

\section{Intestinal measurements and microflora}

No effect of probiotic supplementation on visceral weight or length was observed, except a higher of jejunum ( $\mathrm{P}=0.007)$ and ileum $(\mathrm{P}=0.013)$ weights, 
and a tendency to higher the caecum length $(\mathrm{P}=0.070)$. Pourakbari et al. (2016) also noticed an increase in caecum weight as an effect of multi-strain probiotic supplementation in broilers.

A possible explanation of the enlarged intestinal parts observed in the present work could be the increased length and density of the microvilli of the small intestine and caecum due to the probiotic addition (Yurong et al., 2005).

Table 4. Effect of probiotic addition on relative weight and length of intestinal parts, and digesta $\mathrm{pH}^{1}$

\begin{tabular}{|c|c|c|c|c|c|}
\hline \multicolumn{2}{|l|}{ Item } & Control & Probiotic & SEM & $P$-value \\
\hline \multicolumn{6}{|c|}{ Relative weight and length of intestinal parts (g or cm/100 g BW) } \\
\hline \multirow[t]{2}{*}{ Duodenum } & $\mathrm{g}$ & 0.66 & 0.68 & 0.014 & 0.752 \\
\hline & $\mathrm{cm}$ & 1.44 & 1.43 & 0.035 & 0.844 \\
\hline \multirow[t]{2}{*}{ Jejunum } & $\mathrm{g}$ & $1.54^{\mathrm{b}}$ & $1.77^{\mathrm{a}}$ & 0.051 & 0.007 \\
\hline & $\mathrm{cm}$ & 3.87 & 3.64 & 0.052 & 0.019 \\
\hline \multirow[t]{2}{*}{ Ileum } & $\mathrm{g}$ & $1.10^{\mathrm{b}}$ & $1.20^{\mathrm{a}}$ & 0.040 & 0.013 \\
\hline & $\mathrm{cm}$ & 3.75 & 3.72 & 0.059 & 0.818 \\
\hline \multirow[t]{2}{*}{ Caecum } & $\mathrm{g}$ & 0.60 & 0.63 & 0.014 & 0.113 \\
\hline & $\mathrm{cm}$ & 0.80 & 0.88 & 0.023 & $0.070^{T}$ \\
\hline \multicolumn{6}{|l|}{ Digesta pH } \\
\hline \multicolumn{2}{|l|}{ Duodenum } & 5.95 & 5.84 & 0.032 & 0.178 \\
\hline \multicolumn{2}{|l|}{ Jejunum } & 6.27 & 6.15 & 0.028 & 0.184 \\
\hline \multicolumn{2}{|l|}{ Ileum } & 6.48 & 6.25 & 0.123 & 0.389 \\
\hline \multicolumn{2}{|l|}{ Caecum } & 6.84 & 6.69 & 0.038 & $0.054^{T}$ \\
\hline
\end{tabular}

Note: ${ }^{1} \mathrm{n}=8$ samples per group; SEM, standard error of the mean; $\mathrm{BW}$, body weight.

${ }^{a b}$ Means with different superscript within a row differ significantly $(\mathrm{P}<0.05)$.

Regarding the $\mathrm{pH}$ of intestinal digesta (Table 4), our study results showed that the probiotic addition did not affect the $\mathrm{pH}$ values $(\mathrm{P}>0.05)$; even a tendency to decrease the caecum $\mathrm{pH}$ was noticed $(\mathrm{P}=0.054)$ compared to the basal diet. It was stated that the intestinal digesta $\mathrm{pH}$ is influenced by the diet composition and also by the fermentation activity of intestinal microbiota (Guardia et al., 2011; Tsiouris et al., 2014). The lactic acid produced from lactose fermentation reduced the $\mathrm{pH}$ value of intestinal digesta (Molnar et al., 2018; Jha et al., 2020).

Our study results have shown that probiotic addition tends to decrease the $\mathrm{pH}$ value of caecal digesta (6.69 vs 6.84; $\mathrm{P}=0.054$ ). According to Svihus et al. (2013), caecum represents the primary site for bacterial fermentation in chickens due to its specific habitat. Bacteria metabolize soluble nondigestible carbohydrates into short-chain fatty acids and lactate, which decreases the $\mathrm{pH}$ (Rinttilä and Apajalahti, 2013). Several studies have also shown that lowers $\mathrm{pH}$ may suppress the development of acid-sensitive bacteria from the 
Enterobacteria family (Rinttilä and Apajalahti, 2013; Molnar et al., 2018; Khadem et al., 2018).

Table 5 show the effect on probiotic on the intestinal microflora of broilers at $35 \mathrm{~d}$ of age. It was observed that the Enterobacteria and E. coli counts decrease and Lactobacilli counts and Lactobacilli: E. coli ratio increase in the ileum and caecum due to the probiotic addition $(\mathrm{P}<0.05)$. The samples of intestinal digesta were negative for Salmonella.

Table 5. Effect of probiotic addition on intestinal microflora $\left(\log _{10} \mathrm{cfu} / \mathrm{g}\right)$ of broilers 1

\begin{tabular}{lcccc}
\hline Item & Control & Probiotic & SEM & P-value \\
\hline Ileum & & & & \\
Enterobacteria & $7.212^{\mathrm{a}}$ & $7.167^{\mathrm{b}}$ & 0.008 & 0.043 \\
E. coli & $5.608^{\mathrm{a}}$ & $5.512^{\mathrm{b}}$ & 0.020 & 0.004 \\
Lactobacillus spp. & $6.453^{\mathrm{b}}$ & $6.482^{\mathrm{a}}$ & 0.013 & 0.029 \\
Lactobacillus: E. coli ratio & $1.151^{\mathrm{b}}$ & $1.176^{\mathrm{a}}$ & 0.006 & 0.026 \\
Caecum & & & & \\
Enterobacteria & $8.903^{\mathrm{a}}$ & $8.783^{\mathrm{b}}$ & 0.005 & 0.003 \\
E. coli & $7.762^{\mathrm{a}}$ & $7.660^{\mathrm{b}}$ & 0.030 & 0.006 \\
Lactobacillus spp. & $9.568^{\mathrm{b}}$ & $9.661^{\mathrm{a}}$ & 0.005 & 0.012 \\
Lactobacillus: E. coli ratio & $1.232^{\mathrm{b}}$ & $1.261^{\mathrm{a}}$ & 0.008 & 0.006 \\
\hline
\end{tabular}

Note: ${ }^{1} \mathrm{n}=8$ samples per group; SEM, standard error of the mean.

${ }^{a b}$ Means with different superscript within a row differ significantly $(\mathrm{P}<0.05)$.

Similarly, Peng et al. (2016) reported that L. plantarum in broilers decreased the Enterobacteriaceae, and increased the Lactobacillus count, small intestinal villus height, and faecal volatile fatty acid concentration.

Our recent work indicated that the dietary addition of $L$. acidophilus in Ross 308 broilers significantly decreased the caecum $\mathrm{pH}$, E. coli and Staphylococcus spp. counts and increased the Lactobacillus spp. and lactobacilli: E. coli ratio (Gheorghe et al., 2020). A study by Olnood et al. (2015) evaluated four Lactobacillus strains on Cobb 500 broiler chicks' growth performance and gut microbial profile. These authors reported that the probiotic Lactobacillus spp. higher the total anaerobic bacteria count in the ileum and ceca, and the count of LAB and Lactobacilli in the ceca. Moreover, the probiotics strains tended to decrease the Enterobacteria count in the ileum. It is stated that Lactobacilli has the capability to auto- and co-aggregate; usually, the bacteria with a high auto-aggregation capacity have good adhesion to the mucus and the ability to exclude other microorganisms (Jha et al., 2020).

Other studies (Mountzouris et al., 2007; Vicente et al., 2008; Pourakbari et al., 2016; Ding et al., 2019) have also reported the potential of probiotics 
to modulate the composition of gut microflora of broiler chickens and to suppress the growth of potentially pathogenic bacteria. Giannenas et al. (2012) found that Lactobacillus-based probiotics fed broilers improve the populations of Lactobacillus and Bifidobacterium in the small intestine.

On the contrary, Cengiz et al. (2015) reported that fed Ross 308 broiler chickens with a multi-strain's probiotics supplemented diet did not significantly affect the gut total aerobic and Salmonella populations.

\section{CONCLUSION}

The study results indicated that the probiotic mix (L.acidophilus and $L$. plantarum, 1:1 ratio) used did not significantly influence the productive performance and carcasses traits. The probiotic mixture positively affected broilers' gut microflora due to improving the beneficial bacteria in detrimental to potentially pathogenic bacteria. Further study is still needed to assess the effective concentration of microencapsulated form to enhance their viability during processing and possible interaction or synergy with other feed bio compounds.

\section{ACKNOWLEDGEMENTS}

This study was funded by the Ministry of Research, Innovation and Digitization (Romania), grant 8PCCDI 0473/2018, PC2.

\section{REFERENCES}

Al-Shawi, S.G., Dang, D.S., Yousif, A.Y., Al-Younis, Z.K., Najm, T.A., Matarneh, S.K. 2020. The potential use of probiotics to improve animal health, efficiency, and meat quality: A review. Agriculture 10, 452.

Attia, Y.A., Al-Harthi, M.A., El-Shafey, A.S., Rehab, Y.A., Kim, W.K. 2017. Enhancing tolerance of broiler chickens to heat stress by addition with vitamin E, vitamin C and/or probiotics. Ann Anim Sci. 17, 1-15.

Awad, W.A., Ghareeb, K., Abdel-Raheem, S., Böhm, J. 2009. Effects of dietary inclusion of probiotic and synbiotic on growth performance, organ weights, and intestinal histomorphology of broiler chickens. Poult Sci. $88,49-56$.

Awad, W.A., Ghareeb, K., Bohm, J. 2010. Effect of addition of a probiotic microorganism to broiler diet on intestinal mucosal architecture and electrophysiological parameters. J Anim Physiol Anim Nutr. 94(4), 486-494.

Bajagai, Y.S., Klieve, A.V., Dart, P.J., Bryden, W.L. 2016. Animal Production and Health Div Probiotics. In Animal Nutrition: Production, Impact and Regulation; Food and Agriculture Organization of the United Nations: Rome, Italy. ISBN 978-92-5-109333-7. 
Cengiz, Ö., Köksal, B.H., Tatll, O., Sevim, Ö., Ahsan, U., Üner, A.G., Ulutas, P.A., Beyaz, D., Büyükyörük, S., Yakan, A. 2015. Effect of dietary probiotic and high stocking density on the performance, carcass yield, gut microflora, and stress indicators of broilers. Poult Sci. 94, 2395-2403.

Chen, C., Chen, S., Wang, H. 2017. Effect of supplementation of yeast with bacteriocin and Lactobacillus culture on growth performance, cecal fermentation, microbiota composition, and blood characteristics in broiler chickens. Asian Australas J Anim Sci. 30, 211.

Ciurescu, G., Dumitru, M., Gheorghe, A., Untea, A.E., and R. Drăghici. 2020. Effect of Bacillus subtilis on growth performance, bone mineralization, and bacterial population of broilers fed with different protein sources. Poult Sci. 99(11), 5960-5971.

De Cesare, A., Sala, C., Castellani, G., Astolfi, A., Indio, V., Giardini, A., Manfreda, G. 2020. Effect of Lactobacillus acidophilus D2/CSL (CECT 4529) supplementation in drinking water on chicken crop and caeca microbiome. PLos One 15(1):e0228338.

De Cesare, A., Sirri, F., Manfreda, G., Moniaci, P., Giardini, A., Zampiga, M., Meluzzi, A. 2017. Effect of dietary supplementation with Lactobacillus acidophilus D2/CSL (CECT 4529) on caecum microbioma and productive performance in broiler chickens. PLoS One 12:e0176309.

Deng, Q., Shi, H., Luo, Y., Zhao, H., Liu, N. 2020. Effect of dietary Lactobacilli mixture on Listeria monocytogenes infection and virulence property in broilers. Poult Sci. 99, 3655-3662.

Dierick, N.A. 1989. Biotechnology aids to improve feed and feed digestion: enzymes and fermentation. Arch Anim Nutr. 39(3), 241-261.

Ding, S., Wang, Y., Yan, W., Li, A., Jiang, H., Fang, J. 2019. Effects of Lactobacillus plantarum 15-1 and fructooligosaccharides on the response of broilers to pathogenic Escherichia coli 078 challenge. PLoS One 14(6): e0212079.

Dumitru, M., Tabuc, C., Jurcoane, Ș. 2018. Obtaining a feed additive based of Lactobacillus plantarum strain. Sci. Papers Ser. A. Agron. 61(2), 115122.

Dumitru, M., Sorescu, I., Ciurescu, G., Tabuc, C., Habeanu, M., Chelaru N.R. 2019. In vitro probiotic properties of a lactic acid bacteria isolated from a broiler chicken. Filodiritto-Proceedings 1, 326-332.

Fathi, M.M., Ebeid, T.A., Al-Homidan, I., Soliman, N.K., Abou-Emera, O.K. 2017. Influence of probiotic supplementation on immune response in broilers raised under hot climate. Br Poult Sci. 58, 512-516.

Forte, C., Manuali, E., Abbate, Y., Papa, P., Vieceli, L., Tentellini, M., TrabalzaMarinucci, M., Moscati, L. 2018. Dietary Lactobacillus acidophilus positively influences growth performance, gut morphology, and gut microbiology in rurally reared chickens. Poult Sci. 97, 930-936. 
Gadde, U.D., Kim, W.H., Oh, S.T., Lillehoj, H.S. 2017. Alternatives to antibiotics for maximizing growth performance and feed efficiency in poultry: A review. Anim Health Res Rev. 18, 26-45.

Gheorghe, A., Hăbeanu, M., Tabuc, C., Marin, M. 2019. Effects of dietary pea seeds (Pisum Sativum L. cv. Tudor) on performance, carcass traits, plasma biochemistry and intestinal microflora in broiler chicks. AgroLife Sci J. 8(1), 99-106.

Gheorghe, A., Lefter, N.A., Idriceanu, L., Ropotă, M., Hăbeanu, M. 2020. Effects of dietary extruded linseed and Lactobacillus acidophilus on growth performance, carcass traits, plasma lipoprotein response, and cecal bacterial populations in broiler chicks. Ital J Anim Sci. 19(1), 822-832.

Giannenas, I., Papadopoulos, E., Tsalie, E., Triantafillou, E., Henikl, S., Teichmann, K., Tontis, D. 2012. Assessment of dietary supplementation with probiotics on performance, intestinal morphology and microflora of chickens infected with Eimeria tenella. Vet Parasitol. 188, 31-40.

Giannenas, E., Tsalie, E., Triantafillou, S., Hessenberger, K., Teichmann, M., Mohnl, D. Tontis, D. 2014. Assessment of probiotics supplementation via feed or water on the growth performance, intestinal morphology and microflora of chickens after experimental infection with Eimeria acervulina, Eimeria maxima and Eimeria tenella. Avian Pathol. 43(3), 209-216.

Guardia, S., Konsak, B., Combes, S., Levenez, F., Cauquil, L., Guillot, J.F., MoreauVauzelle, C., Lessire, M., Juin, H., Gabriel, I. 2011. Effects of stocking density on the growth performance and digestive microbiota of broiler chickens. Poult Sci. 90, 1878-1889.

Hardy, H., Harris, J., Lyon, E., Beal, J., Foey, A.D. 2013. Probiotics, prebiotics and immunomodulation of gut mucosal defences: Homeostasis and immunopathology. Nutrients 5, 1869-1912.

Hăbeanu, M., Tabuc, C., Gheorghe, A., Ropota, M., Dumitru, M., Călin, L., Mihalcea, T., Palade, M. 2016. Preliminary study on the interrelation between sow milk quality and litter performance in relation to their health. Scientific Papers-Animal Science Series,.66, 35-40.

Hong, J., Steiner, T., Aufy, A., Lien, T. 2012. Effects of supplemental essential oil on growth performance, lipid metabolites and immunity, intestinal characteristics, microbiota and carcass traits in broilers. Livest Sci. 144, 253-262.

Hossain, M., Ko, S., Kim, G., Firman, J., Yang, C. 2012. Evaluation of probiotic strains for development of fermented Alisma canaliculatum and their effects on broiler chickens. Poult Sci. 91, 3121-3131.

Khadem, A., Louren, M., Delezie, E., Maertens, L., Goderis, A., Mombaerts, R., Janssens, G.P.J. 2018. Comparing two techniques for viscosity 
measurements in poultry feedstuffs: Does it render similar conclusions? Poult Sci. 97, 3138-3148.

Lokapirnasari, W.P., Sahidu, A.M., Maslachah, L., Sabdoningrum, E.K., Yulianto, A.B. 2020. Effect of Lactobacillus Casei and Lactobacillus acidophilus in laying hens challenged by Escherichia coli infection. Sains Malays. 49, 1237-1244.

Midilli, M., Tuncer, S.D. 2001. The effects of enzyme and probiotic supplementation to diets on broiler performance. Turk J Vet Anim Sci. 25(6), 895-903.

Molnar, A., Dublecz, F., Pál, L., Wágner, L., Hess, C., Hess, M., Husvéth, F., Dublecz, K. 2018. Soluble nondigestible carbohydrates improve intestinal function and increase caecal coliform load in broiler chickens. J Anim Physiol Anim Nutr. 102, 1615-1624.

Mountzouris, K.C., Tsirtsikos, P., Kalamara, E., Nitsch, S., Schatzmayr, G., Fegeros, K. 2007. Evaluation of the efficacy of a probiotic containing Lactobacillus, Bifidobacterium, Enterococcus, and Pediococcus strains in promoting broiler performance and modulating cecal microflora composition and metabolic activities. Poult Sci. 86, 309-317.

Naseem, S., Rahman, S.U., Shafee, M., Sheikh, A.A., Khan, A. 2012. Immunomodulatory and growth-promoting effect of a probiotic supplemented in the feed of broiler chicks vaccinated against infectious bursal disease. Braz J Poult Sci. 14, 109-113.

NRC (National Research Council). Nutrient Requirements of Poultry. 9th rev ed. The National Academies Press, Washington D.C USA; 1994.

OJEU (Official Journal of the European Union). Commission Regulation (EC) No. 152/2009 laying down the methods of sampling and analysis for the official control of feed. 2009.

Olnood, C.G., Beski, S.S.M., Choct, M., Iji, P.A. 2015. Novel probiotics: Their effects on growth performance, gut development, microbial community and activity of broiler chickens. Anim Nutr. 1, 184-191.

Peng, Q., Zeng, X.F., Zhu, J.L., Wang, S., Liu, X.T., Hou, C.L., Thacker, P.A., Qiao, S.Y. 2016. Effects of dietary Lactobacillus plantarum B1 on growth performance, intestinal microbiota, and short chain fatty acid profiles in broiler chickens, Poult Sci, 95(4), 893-900.

Pourakbari, M., Seidavi, A., Asadpour, L., Martínez, A. 2016. Probiotic level effects on growth performance, carcass traits, blood parameters, cecal microbiota, and immune response of broilers. An Acad Bras Ciênc. 88, 1011-1021.

Rinttilä, T., Apajalahti, J. 2013. Intestinal microbiota and metabolitesImplications for broiler chicken health and performance. J Appl Poult Res. 22, 647-658.

Shokryazdan, P., Sie,o C.C., Kalavathy, R., Liang, J.B., Alitheen, N.B., Faseleh, J.M. 2014. Probiotic potential of Lactobacillus strains with antimicrobial 
activity against some human pathogenic strains. Biomed Res Int. 2, 116.

Shokryazdan, P., Faseleh, J.M., Liang, J.B., Ramasamy, K., Sieo, C.C., Ho, Y.W. 2017. Effects of a Lactobacillus salivarius mixture on performance, intestinal health and serum lipids of broiler chickens. PLoS ONE 12(5), e0175959.

Sorescu, I., Dumitru, M., Ciurescu, G. 2019. Lactobacillus spp. and Enterococcus faecium strains isolation, identification, preservation and quantitative determinations from turkey gut content. Rom Biotechnol Lett. 24(1), 41-49.

Svihus, B., Choct, M., Classen, H.L. 2013. Function and nutritional roles of the avian caeca: A review. World's Poult Sci J. 69, 249-264.

Timmerman, H.M., Veldman, A., van der Elsen, E., Rombouts, F.M., Beynen. A.C. 2006. Mortality and growth performance of broilers given drinking water supplemented with chicken-specific probiotics. Poult Sci. 85, 1383-1388.

Tsiouris, V., Georgopoulou, I., Batzios, C., Papaioannou, N., Ducatelle, R., Fortomaris, P. 2014. Temporary feed restriction partially protects broilers from necrotic enteritis. Avian Pathol. 43, 139-145.

Vicente, J.L., Torres-Rodriguez, A., Higgins, S.E., Pixley, C., Tellez, G., Donoghue, A.M., Hargis, B.M. 2008. Effect of a selected Lactobacillus spp.-based probiotic on Salmonella enterica serovar Enteritidis-infected broiler chicks. Avian Dis. 52(1), 143-146.

Waititu, S.M., Yitbarek, A., Matini, E., Echeverry, H., Kiarie, E., RodriguezLecompte, J.C., Nyachoti, C.M. 2014. Effect of supplementing direct-fed microbials on broiler performance, nutrient digestibilities, and immune responses. Poult Sci. 93(3), 625-635.

Yurong, Y., Ruiping, S., Shimin, Z., Yibao, J. 2005. Effect of probiotics on intestinal mucosal immunity and ultrastructure of cecal tonsils of chickens. Arch Anim Nutr. 59, 237-246. 